\title{
Análise das demandas judiciais \\ para o fornecimento de medicamentos pela Secretaria de Estado da Saúde de Santa Catarina nos anos de 2003 e 2004
}

\author{
Situation of lawsuits concerning the access to medical products \\ by the Health Department of Santa Catarina State, Brazil, \\ during the years 2003 and 2004
}

Januária Ramos Pereira ${ }^{1}$

Rosana I sabel dos Santos ${ }^{1}$

José M iguel do Nascimento Junior ${ }^{2}$

Eloir Paulo Schenkel ${ }^{1}$

\footnotetext{
${ }^{1}$ Departamento de

Farmácia, U niversidade da Região deJoinville. Campus Universitário $\mathrm{s} / \mathrm{n}$ ㅇ, Bom Retiro. 89219-905 Joinville SC.

januariaramos@gmail.com

2 Universidade do Vale do Itajaí.
}

Abstract Thisstudy describes thesituation of lawsuits concerning the access to medical products by the Health Department of Santa Catarina State (SES/SC), Brazil, during the years of 2003 and 2004. The variables considered were: declared illnesses, medicines demanded, prescription origin, possible alternatives therapeutics in the Santa Catarina State Register of Essential Medicines (Resme), the medicines registration at the $\mathrm{Na}$ tional Health Surveillance Agency (Anvisa) and total expenditure. 622 lawsuits were filed. Total expenditure was R\$11,333,750,00 (Brazilian Reais). Private health care was the source of $56 \%$ of the prescriptions. $\mathrm{H}$ epatitis $\mathrm{C}$ and rheumatoid arthritis were the most commonly diseases involved. About $40 \%$ of requested drugs were on the Resme. $6.2 \%$ of required drugs were approved in Brazil after 2000. PEG-Interferon and Infliximab were responsible for $46 \%$ of total expenditure. There were still some cases of drugs or indications not registered at Anvisa. These results indicate the need to reassess the list of medicines regularly provided by the SES/SC, and also to improve accessibility to (and information concerning) Programs of medicines distribution. These measures may potentially reduce the number of lawsuits filed against the State.

Key words M edicines, Lawsuits, Brazilian Unified $\mathrm{H}$ ealth System (SUS)
Resumo Neste trabalho, é analisada a situação dos processos judiciais contra a Secretaria deEstado de Saúde de Santa Catarina determinando fornecimento de medicamentos em 2003 e 2004. As variáveis consideradas foram: patologia declarada, medicamento solicitado, origem da prescrição, possíveis alternativas terapêuticas na Relação Estadual de M edicamentos (Resme), registro dos medicamentos na Agência Nacional de Vigilância Sanitária (Anvisa) e custos totais. Foram analisados 622 processos, com gasto de $\mathrm{R} \$ 11.333 .750,00$. Os serviços privados de saúde originaram $56 \%$ das prescrições. $\mathrm{H}$ epatite $\mathrm{C}$ e artrite reumatoide foram as doenças mais referidas. Em 40\% dos casos, os produtos faziam parte da Resme. Dos produtos solicitados, 6,2\% tiveram a sua comercialização iniciada no Brasil a partir do ano 2000, destacando-se Interferon Pequilado e Infliximabe, responsáveis por $46 \%$ do total dos gastos. Alguns processos envolviam medicamentos que não possuíam registro na Anvisa, e houve casos em que a indicação de uso do medicamento não estava aprovada no país. Os resultados indicam que a reavaliação dos elencos de medicamentos padronizados e a melhoria no acesso aos tratamentos, aliadas à meIhor divulgação dos programas de distribuição de medicamentos, são medidas que potencialmente poderão reduzir o número de processos judiciais. Palavras-chave M edicamentos, Processos judiciais, Sistema Ú nico de Saúde 
Introdução

A garantia de acesso aos medicamentos, por parte do Estado, observados os preceitos do uso racional deles, representa uma importante estraté gia para a redução da morbimortalidade associada a doenças, particularmente em países degrandeiniquidade social como o Brasil. Caberessaltar que 0 acesso não pode estar restrito à disponibilização dos medicamentos, pois para assegurar que o seu uso seja realizado de forma racional e seguro, é necessário desenvolver uma série de ações articuladas, cujo conjunto, atualmente, é denominado de Assistência Farmacêutica. Tais ações vão da pesquisa e desenvolvimento de fármacos e medicamentos à seleção e provisão daqueles indispensáveis às necessidades de uma comunidade específica, incluindo-se a prescrição, a dispensação e o posterior acompanhamento e avaliação do seu uso.

Tão recente quanto essa definição são as tentativas de se estabelecer um projeto nacional de ordenamento e desenvolvimento de tal abrangência para o setor. Assim, embora o direito à Assistência Farmacêutica tenha sido explicitado na Lei Orgânica da Saúde (n 8.080), de 1990, a menção a um serviço qualificado, integrante do conjunto das políticas públicas ${ }^{1,2}$, somente ocorreu com a edição da Política Nacional de M edicamentos, em 1998, e posteriormente, na Política $\mathrm{N}$ acional de Assistência Farmacêutica, estabelecida em 2004. Tendo em vista que uma parcela considerável da população brasileira não tem acesso aos medicamentos, conforme apontado em diferentes documentos, entre os quais os registros da CPI dos M edicamentos ocorrida em $2000^{3}$, equeas intoxicações com o uso inadequado de medicamentos também são consideráveis ${ }^{4}$, a inclusão da Assistência Farmacêutica como parte integrante do direito à saúde é fundamental para que este se realize.

Como direito social, a saúde, juntamentecom o direito à educação e ao trabalho, tem como função propiciar a cada indivíduo as condições de ter o poder para fazer aquilo que é livre para fazer. Em outras palavras, os direitos sociais garantem a equiparação dos indivíduos para que, sob as mesmas condições, tenham a liberdade para se desenvolver. Além de protegerem o interesse primário do indivíduo na garantia de sua independência social, servem ao interesse geral da sociedade da qual o indivíduo faz parte. Tais direitos são afirmados nas democracias contemporâneas, ditas sociais, pelo reconhecimento da "pessoa social", além da "pessoa moral", já reco- nhecida pelas democracias liberais como a portadora dos direitos deliberdade 5 . Porém, enquanto os direitos de liberdade remetem à atuação negativa do Estado, os direitos sociais requerem a intervenção direta e positiva do Estado, através da prestação de serviços.

Assim, a concretização ao direito à Assistência Farmacêutica, juntamente com as políticas específicas, exige a estruturação dos serviços públicos. Embora ainda não se possa falar de serviços de Assistência Farmacêutica, o acesso aos medicamentos no Sistema Único deSaúde, desde o final da década de 90 , vem sendo construído através de programas governamentais dirigidos às principais enfermidades que acometem a população. Em certa medida, esses programas acompanham a organização da atenção à saúde em seus diferentes níveis de complexidade.

Entretanto, independentee paralelamenteao ordenamento governamental para as questões de saúde, temos assistido à intervenção do Poder Judiciário determinando o fornecimento de medicamentos pelo Estado, sob a âncora da positivação da saúde como "direito de todos e dever do Estado", efetuada com a sua inscrição na Constituição Federal (artigo 196). É um tema polêmico, já que, como norma constitucional definidora de direito social, apresenta na própria Constituição Brasileira os dispositivos específicos que vinculam recursos e geram direitos subjetivos à população para cobrar do Governo uma atuação positiva nestes setores sociais com a criação de políticas públicas setoriais ${ }^{6}$. Conforme Appio ${ }^{7}$, os direitos sociais têm um custo que deve ser suportado pelo Estado e, nesse sentido, existe um conflito direto entreo direito à vida de um cidadão, o qual busca através do Poder Judiciário a sua sobrevivência, e o direito à vida de outros cidadãos, os quais dependem do orçamento público para sobreviver. Além disso, as políticas públicas partem deum ideal dejustiça distributiva, cuja finalidade é assegurar um tratamento igual aos cidadãos iguais edesigual aos desiguais. $\mathrm{Na}$ opinião desse autor, a decisão acerca das prioridades a serem conferidas pelo Estado nesta área éessencialmente uma decisão política emoral, que refoge do âmbito do controle judicial.

Em trabalho recentementepublicado sobrea judicialização demedicamentos no estado deSão Paulo, M arques e Dallari ${ }^{8}$ concluem que as decisões judiciais vêm influindo na função de tomada de decisões col etivas com base nas necessidades individuais dos autores e, mais grave que isso, tais ações ainda podem acobertar os inter esses de determinados laboratórios farmacêuticos, responsá- 
veis pela comercialização de inovações terapêuticas inacessíveis financeiramente aos autores.

Esse fenômeno não ocorreapenas no Brasil e pode assumir diferentes versões. A Agência Reuters ${ }^{9}$, em 2006, noticiou que, pela primeiravez na história do $\mathrm{N}$ ational Institutefor $\mathrm{H}$ ealth and $\mathrm{Cli}$ nical Excellence (NICE), da Inglaterra, uma decisão sua estava sendo questionada na justiça: os laboratórios produtores do campeão de vendas Aricept, Eisai Co. Ltd. e Pfizer Inc., não conformados com restrição imposta pelo NICE quanto ao acesso àquele medicamento na rede pública de serviços, em decorrência de suas conclusões sobrecusto-efetividade, estavam, via judicial, tentando impor a sua inclusão sob o financiamento do Estado.

No Brasil, o fenômeno érecentee de proporções alarmantes. Exemplo disso é relatado em um trabalho recente, referente à demanda de medicamentos através de processos judiciais, encaminhados à Secretaria de Estado da Saúde do Rio de Janeiro (SES/RJ), nos anos de 1991 a $2002^{10}$. Da mesma forma, dados do Superior Tribunal deJustiça do Brasil (STJ) indicam um crescimento do número de processos relacionados ao fornecimento de medicamentos, de apenas

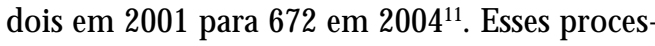
sos obrigam o Estado a fornecer, de imediato, 0 produto, de forma desarticulada com processo de organização da assistência farmacêutica, contribuindo para a desorganização do serviço e ônus para o erário. No intuito de contribuir para o melhor entendimento dessa questão, o presente trabal ho descreve a situação dos processos judiciais impetrados contra o estado de Santa Catarina, determinando fornecimento de medicamentos nos anos de 2003 e 2004.

\section{M etodologia}

Foi realizado um estudo descritivo e transversal, compreendendo os anos de 2003 e 2004. Os dados relativos aos processos judiciais no estado de Santa Catarina foram obtidos junto à Diretoria de Assistência Farmacêutica da Secretaria de Estado da Saúde de Santa Catarina (DIAF/SES).

Os dados coletados incluíram: número de processos judiciais demandando o fornecimento de medicamentos; número de produtos por processo judicial; produtos solicitados; municípios responsáveis por maior número de processos; tratamento a que se destinavam os medicamentos; o condutor da ação (defensoria pública, escritório modelo eescritório particular) eavincu- lação do prescritor ao sistema público de saúde ou a consultório particular. Esteúltimo dado foi observado através da prescrição médica anexada ao processo.

Com relação aos custos individuais com medicamentos solicitados por via judicial, os dados apresentados são de 2004. Para obtenção de dados fidedignos, foi realizada uma busca manual em todas as notas fiscais de compra desses medicamentos em 2004.

Foram levantados dados a respeito do ano de introdução dos produtos no mercado nacional. Esses dados foram obtidos através de solicitações, via correio eletrônico ou por telefone, junto aos laboratórios produtores.

Adicionalmente, os produtos foram categorizados e analisados de acordo com a indicação encontrada no processo. Deve-se esclarecer que os processos judiciais muitas vezes abrangem mais de um produto, podendo envolver mais de uma indicação clínica. N esses casos, a análise foi realizada considerando cada produto como uma solicitação.

As bulas dos medicamentos mais solicitados dentro de cada grupo foram consultadas, buscando-se verificar se as indicações referidas nos processosjudiciais estavam deacordo com aquelas aprovadas no Brasil. Utilizaram-se as bulas como referência das indicações aprovadas no país devido à dificuldade de acesso aos documentos de registro e considerando a existência de um bulário oficial, o Compêndio de Bulas de M edicamentos (CBM) editado pela A gência N acional deVigilância Sanitária (Anvisa) em 2005.

Assolicitações encaminhadas por via judicial foram confrontadas com as listas demedicamentos padronizados pela Secretaria de Estado da Saúde e/ou M inistério da Saúde e disponibilizadas através dos programas vigentes durante 0 período analisado. Desta forma, foi possível determinar quanto da demanda judicial visava à obtenção de medicamentos que já estavam padronizados, eventualmentedisponíveis através de programas específicos, bem como da percentagem de medicamentos ainda não padronizados.

Com relação aos medicamentos inseridos nos programas vigentes durante o período analisado, buscaram-se nos processos informações que pudessem indicar a utilização dessa via antes do estabelecimento da demandajudicial.

Dados relacionadosà demanda atendida através dos programas governamentais vigentes foram obtidos com a Gerência de Programação e Gerência deSuprimentos da Diretoria deAssistência Farmacêutica e através dos relatórios de ges- 
tão elaborados pela Diretoria de Assistência Farmacêutica. Informações relacionadas aos custos com a aquisição de medicamentos para dispensação através dos programas e por via judicial foram obtidas com a Gerência de Administração da Diretoria deAssistência Farmacêutica. 0 estudo foi aprovado pela Comissão de Ética em Pesquisa da Universidade Federal de Santa Catarina.

\section{Resultados}

Os registros de ações judiciais para o fornecimento demedicamentos pela Secretaria deEstado da Saúde de Santa Catarina (SES/SC) iniciaram-se em 2000. Naquele ano foram registrados apenas dois processos, provenientes da cidade de Florianópolis, solicitando oito medicamentos, em sua maioria indicados para o tratamento de problemas cardiovasculares. Como demandaram pouco custo financeiro, não houve registro dos quantitativos específicos com cada um dos produtos fornecidos.

A Tabela 1 apresenta 0 aumento dos gastos com medicamentos em ações judiciais edo número de ações recebidas na SES/SC a partir de 2000. Ressalta-se que os valores dos custos (em reais) referem-se somente ao que foi gasto na aquisição dos medicamentos fornecidos; não foram computados os gastos inerentes aos recursos humanos e físicos envolvidos, nem os referentes à própria tramitação dos processos. 0 número médio de medicamentos solicitados por processos teve um ligeiro decréscimo, de quatro, em 2000, para 1,8, em 2004. Entretanto, se for considerado 0 gasto médio por processo, observa-se um incremento de $326 \%$ dos anos 2001/2002 para os anos $2003 / 2004$, indicando que os medicamentos solicitados por processo são de custo bastante superior, fato confirmado quando são estimados os gastos médios por medicamento.
Os custos para 0 atendimento das demandas judiciais representaram em 2002 aproximadamente $0,6 \%$ do valor total gasto pela SES/SC (R \$ 23 milhões) com a aquisição de medicamentos. Em 2003 e 2004 as demandas judiciais foram responsáveis, respectivamente, por aproximadamente 7,5\% e 11,5\% dos val orestotais gastos com medicamentos pela SES/SC ( $R \$ 37,5$ milhoes e $\mathrm{R} \$ 56$ milhões).

Em relação ao período em que os processos foram analisados (anos de 2003 e 2004), observou-se que:

- foram fornecidos 388 produtos diferentes, em 1.163 solicitações individualizadas;

. $404(65 \%)$ dos 622 processos judiciais atendidos estavam relacionados com apenas um produto, 93 (15\%) com dois produtos, 48 (7,8\%) com três produtos e $76(12,2 \%)$ demandavam mais de três produtos;

. houve predomínio de processos oriundos depacientes moradores da região da GrandeFIorianópolis (cerca de $45 \%$ ), sendo que os municípios deFlorianópolis (21,7\%) eSão José( $10,2 \%$ ) foram os responsáveis pelos maiores números;

. $367(59 \%)$ dos processos foram conduzidos por escritórios deadvocacia particulares, 218 (35\%) pela defensoria pública e 37 (6\%) por escritórios modelo de universidades de Santa Catarina;

. em 347 processos (55,8\%), a prescrição anexada era proveniente de serviços privados de saúde; em 205 processos (33\%) a prescrição era originária do sistema público de saúde; eem setenta processos (11,3\%) não foi possível estabelecer essa relação devido à falta da prescrição médica (atéo início de 2005, a Diretoria de Assistência Farmacêutica não exigia quea prescrição médica estivesse anexada ao processo para que o medicamento fosse liberado). Essa proporção varia conformea indicação detratamento presenteno processo judicial, sendo marcante nos casos de medicamentos para oncologia, hepatite viral C, cirrose biliar

Tabela 1. Gastos com medicamentos em ações judiciais e número de ações recebidas no período de 2000 a 2004.

\begin{tabular}{|c|c|c|c|c|c|}
\hline \multirow{2}{*}{ Ano } & \multirow{2}{*}{$\begin{array}{c}\text { Número de } \\
\text { novos processos }\end{array}$} & \multirow{2}{*}{$\begin{array}{c}\text { Número de } \\
\text { medicamentos solicitados }\end{array}$} & \multirow{2}{*}{$\begin{array}{c}\text { Gasto total por } \\
\text { ano, em reais }(R \$)\end{array}$} & \multicolumn{2}{|c|}{ Gasto médio (R\$) } \\
\hline & & & & $\begin{array}{l}\text { Por } \\
\text { processo }\end{array}$ & $\begin{array}{l}\text { Por medicamento } \\
\text { fornecido }\end{array}$ \\
\hline 2000 & 2 & 8 & - & - & - \\
\hline 2001 & 7 & 19 & $38.362,07$ & $5.480,30$ & $2.019,06$ \\
\hline 2002 & 34 & 84 & $131.452,07$ & $3.866,27$ & $1.564,91$ \\
\hline 2003 & 178 & 365 & $2.814 .786,35$ & $15.813,41$ & $7.711,74$ \\
\hline 2004 & 444 & 798 & $6.510 .045,48$ & $14.662,27$ & $8.157,95$ \\
\hline Total & 665 & 1.274 & $9.494 .645,97$ & - & - \\
\hline
\end{tabular}


primária ecolangiteesclerosante primária, artrite reumatoide, espondilite anquilosante e artrite psoriática, osteoporose e hipertensão pulmonar, em quehá predomínio de prescrições provenientes do serviço privado de saúde;

. dos 388 produtos encontrados nas 1.163 solicitações analisadas, $24(6,2 \%)$ tiveram a sua comercialização iniciada no Brasil a partir do ano 2000. Destes, destacam-se Interferon Pequilado e Infliximabe, responsáveis, respectivamente, por $8,8 \%$ e $6,3 \%$ das solicitaçoes e por $23,3 \%$ e $22,3 \%$ do total dos gastos;

. no contexto de "novidade terapêutica", cabe destacar que foram encontrados processos envolvendo medicamentos que ainda não possuíam registro junto àA gência $\mathrm{N}$ acional deV igilância Sanitária. Esses medicamentos (gefitinibe, cetuximabe, enfurvitida, adefovir e trióxido de arsênico) representaram 1,4\% dos produtos fornecidos ( 11 num total de 798) duranteo ano de 2004 , e acarretaram um gasto de $2,7 \%$ ( $R \$$ $175.005,00)$ do total gasto com a aquisição de medicamentos para 0 atendimento das demandas judiciais. Além disso, por se tratar de medicamentos importados, o custo, em termos de pessoal e tempo dispendidos, é bem maior do que para o fornecimento de produtos disponíveis no mercado nacional.

Osgrupos deindicações mais encontrados nos processos analisados e o montante gasto com a aquisição de medicamentos para cada um desses grupos são apresentados na Tabela 2. N esses gru- pos, foram encontrados 42 casos envolvendo o uso em indicações que ainda não eram aprovadas no país. Incluem-se aqui, entre outros, os casos de solicitação de micofenolato de mofetila para nefrite lúpica e infliximabe para artritre psoriática.

A maior parte dos medicamentos fornecidos por essa via não tinham financiamento previsto através de um dos programas vigentes, ou seja, foram categorizados como não padronizados. Esta categoria continha 252 produtos diferentes e representou $62,2 \%$ ( 723 solicitações) dos 1.163 produtos fornecidos. Para al gumas dessas situações, não havia tratamento disponibilizado durante o período analisado. Incluem-se aqui os casos de artrite psoriática e Doença Pulmonar Obstrutiva Crônica (DPOC). No entanto, em al gumas das indicações encontradas nos processos, apesar de o medicamento solicitado não estar padronizado, havia algum outro tratamento disponível (Quadro 1). Nos processos judiciais, em geral, não constavam as justificativas a respeito de motivos pelos quais os medicamentos disponibilizados não estavam sendo utilizados.

Em relação à vinculação a programas governamentais, as 1.163 solicitações analisadas continham medicamentos dos programas:

(1) M edicamentos Excepcionais/Alto Custo - 49 produtos diferentes em um total de 307 solicitações $(26,4 \%)$;

b) Incentivo à Assistência Farmacêutica Básica - 12 produtos diferentes em um total de 28 solicitações $(2,4 \%)$;

Tabela 2. Principais indicações encontradas nos processos judiciais encaminhados nos anos de 2003 e 2004 e custo estimado para cada grupo (valores de 2004).

\begin{tabular}{|c|c|c|}
\hline Indicação & Número de processos & $\begin{array}{c}\text { Custo estimado em } \\
2004(\mathrm{R} \$)\end{array}$ \\
\hline $\begin{array}{l}\text { Artrite reumatoide, espondilite anquilosante e artrite } \\
\text { psoriática }\end{array}$ & 111 & $2.175 .71,00$ \\
\hline Hepatite viral C & 103 & $1.838 .864,00$ \\
\hline Cardiopatia isquêmica e hipertensão arterial sistêmica & 65 & 26.551 \\
\hline M edicamentos para oncologia & 43 & 565.233 \\
\hline Diabetes & 36 & \\
\hline Doença pulmonar obstrutiva crônica e asma & 35 & 27.219 \\
\hline Doença de Parkinson & 22 & 38.426 \\
\hline Epilepsia & 19 & 26.639 \\
\hline $\begin{array}{l}\text { Depressão, transtorno obsessivo-compulsivo e transtorno } \\
\text { bipolar }\end{array}$ & 18 & 18.723 \\
\hline Nefrite lúpica & 17 & 112.761 \\
\hline Cirrose biliar primária e colangite esclerosante primária & 10 & 21.761 \\
\hline Hipertensão pulmonar & 09 & 297.241 \\
\hline Osteoporose & 09 & 49.938 \\
\hline
\end{tabular}


Quadro 1. Principais indicações terapêuticas encontradas nos processos judiciais analisados, medicamentos mais solicitados e medicamentos disponibilizados pela SES/SC.

\begin{tabular}{|l|l|l|}
\hline \multicolumn{1}{|c|}{ Indicações } & \multicolumn{1}{|c|}{ Medicamentos mais solicitados } & \multicolumn{1}{c|}{ M edicamentos padronizados } \\
\hline Artrite reumatoide & $\begin{array}{l}\text { infliximabe, leflunomida, } \\
\text { etanercepte, adalimumabe }\end{array}$ & $\begin{array}{l}\text { hidroxicloroquina, sulfassalazina, } \\
\text { azatioprina, ciclosporina }\end{array}$ \\
\hline Espondilite anquilosante & infliximabe & sulfassalazina \\
\hline $\begin{array}{l}\text { Cardiopatia isquêmaica e } \\
\text { hipertensão arterial sistêmica }\end{array}$ & $\begin{array}{l}\text { propatilnitrato, clopidogrel, enalapril, } \\
\text { carvedilol, sinvastatina }\end{array}$ & $\begin{array}{l}\text { hidroclortiazida, } \\
\text { captoprilfurosemida, propranolol }\end{array}$ \\
\hline Diabetes & insulina glargina & $\begin{array}{l}\text { insulina NPH, } \\
\text { metformina,glibenclamida }\end{array}$ \\
\hline Asma & $\begin{array}{l}\text { formoterol 12 mcg,budesonida 200 } \\
\text { mcg, salmeterol/ } \\
\text { fluticasonaformoterol/budesonida } \\
12 / 400\end{array}$ & $\begin{array}{l}\text { formoterol 12 mcg,budesonida } \\
200 \text { mcg,beclometasona }\end{array}$ \\
\hline Doença de Parkinson & levodopa/benserazida & $\begin{array}{l}\text { pramipexol, } \\
\text { bromocriptina,selegenina, } \\
\text { levodopa/carbidopa }\end{array}$ \\
\hline $\begin{array}{l}\text { Epilepsia } \\
\text { e transtorno bipolar }\end{array}$ & $\begin{array}{l}\text { oxcarbazepina, topiramato, ácido } \\
\text { valproico, carbamazepina CR } 400 \text { mg }\end{array}$ & $\begin{array}{l}\text { lamotrigina, vigabatrina, } \\
\text { carbamazepina, fenitoína, } \\
\text { fenobarbital }\end{array}$ \\
\hline N efrite lúpica & $\begin{array}{l}\text { clonazepan, paroxetina, venlafaxina } \\
\text { diazepam, amitriptilina, } \\
\text { imipramina }\end{array}$ \\
\hline 'Transtorno obsato de mofetila & azatioprina, ciclosporina \\
\hline
\end{tabular}

${ }^{*}$ Transtorno obsessivo-compulsivo.

c) Saúde M ental - cinco produtos diferentes em um total de 17 solicitações (1,5\%);

d) Medicamentos Estratégicos - seis produtos diferentes em um total de 16 solicitações $(1,4 \%)$;

e) Mucoviscidose/Fibrose Cística, dois produtos diferentes em um total de 12 solicitações $(1,0 \%)$.

Em relação às solicitações envolvendo produtos do Programa deM edicamentos Excepcionais, foi possível verificar, por meio do programa de gerenciamento dos M edicamentos Excepcionais em Santa Catarina (M EDEXP), se o paciente havia buscado a via administrativa anteriormente à via judicial. Para os casos afirmativos, os relatórios gerados também permitiram analisar as razões pelas quais as solicitações administrativasnão foram atendidas, ou seja, por quais motivos os pacientes, quando solicitaram os medicamentos através do Programa de M edicamentos Excepcionais, não foram atendidos (Tabela 3).

Um número de produtos de difícil categorização como medicamento foi incluído em uma classe denominada "outros" (5,1\%). Esse grupo incluiu produtos como fitas reativas para glicemia, glicosímetro, fraldas descartáveis, lancetas, seringas e sondas.

\section{Discussão}

Os números demonstram que a judicialização relacionada ao fornecimento demedicamentosse trata de um fenômeno recenteno estado deSanta Catarina, mas com taxas de crescimento assustadoras, tanto no número de novos processos ou solicitações quanto nos gastos, em reais. TrabaIhos recentes so bre o assunto sugerem que o mesmo ocorre em outros estados 8,10,12, embora, até 0 momento, não haja levantamento do número total desses processos no Brasil, nem do gasto gerado pelas decisões favoráveis aos usuários.

Em cerca de $45 \%$ dos processos judiciais, os impetrantes residiam na região da Grande Florianópolis. Tendo em vista que os primeiros processos também tiveram sua origem nessa região, pode-se associar o número elevado a uma certa "tradição" já difundida entre pacientes e prescrito- 
Tabela 3. Número de pacientes que buscaram medicamentos através do Programa de Medicamentos Excepcionais anteriormente à via judicial.

\begin{tabular}{|c|c|c|c|c|}
\hline Indicações & $\begin{array}{l}\text { No de } \\
\text { processos } \\
\text { judiciais* }\end{array}$ & Medicamento solicitado & $\begin{array}{l}\text { № solicitações } \\
\text { pela via } \\
\text { administrativa }\end{array}$ & Motivo de indeferimento \\
\hline Hepatite viral C & 103 & interferon peguilado & $68(66 \%)$ & Genótipo viral 03 \\
\hline Cardiopatia isquêmica & 22 & sinvastatina & $2(9 \%)$ & $\begin{array}{l}\text { Valor de LDL-colesterol abaixo do } \\
\text { estipulado pelos critérios de } \\
\text { inclusão do Programa. }\end{array}$ \\
\hline N efrite lúpica & 17 & micofenolato de mofetila & $7(41 \%)$ & Doença não incluída no Programa \\
\hline Oncologia & 14 & acetato de gosserrelina & $3(21 \%)$ & Doença não incluída no Programa \\
\hline Doença de Parkinson & 7 & pramipexol & $1(14 \%)$ & Documentação incompleta \\
\hline Asma & 3 & formoterol/budesonida & $2(67 \%)$ & Documentação incompleta \\
\hline
\end{tabular}

${ }^{*}$ Considera apenas os processos envolvendo medicamentos do Programa de M edicamentos Excepcionais.

res. Dessa forma, pode-se esperar que as regiões com ainda baixo número de processos venham a ter um rápido acréscimo nos próximos anos.

Conforme a Pesquisa Nacional por Amostra de Domicílios (PNAD) ${ }^{13}$, cerca de $70 \%$ da população brasileira é considerada SUS-dependente, ou seja, que não dispõe de recursos financeiros para os gastos médicos. Considerando que foi observado um predomínio de prescrições originárias no serviço privado, pode-se afirmar que há um público "misto", capaz de custear consultas e eventuais exames, diretamente ou por meio da medicina suplementar, mas que recorre ao Sistema Único de Saúde para a obtenção dos medicamentos.

$\mathrm{N}$ as demandas judiciais para o tratamento de hepatite viral $C$, oncologia, artrite reumatoide, espondilite anquilosante e osteoporose, situações em que foi observado el evado predomínio de prescrições do serviço privado, os medicamentos solicitados eram padronizados mas os solicitantes não aten diam aos critérios de inclusão dos Protocolos Clínicos e Diretrizes Terapêuticas do Ministério da Saúde, ou não eram padronizados. Caberia uma nova investigação para averiguar o quanto isso se deve à inadequações dos programas (quanto ao elenco de medicamentos ou aos critérios de inclusão para essas situações clínicas) ou à não adesão dos médicos do serviço privado às normas dos programas, quer por desconhecimento, quer por desrespeito a elas.

Em algumas situações, apesar de o medicamento solicitado não estar padronizado, havia algum outro tratamento disponível (Quadro 1). Ainda que em al gumas situações houvesse justificativa para a padronização do medicamentos solicitado, como no caso do infliximabe para artrite reumatoide, o fato de não constarem nos processos o grau de severidade da doença e a descrição de tratamentos anteriores impossibilita a avaliação da real necessidade desses produtos.

A partir de 2002, não apenas os gastos com a demanda judicial cresceram significativamente, mas também os gastos totais com medicamentos. Esta última situação é facilmente justificada pela ampliação do el enco do Programa de M edicamentos Excepcionais. Entretanto, essefato parece também ter contribuído, paradoxalmente, para os gastos com a demanda judicial: os medicamentos mais solicitados por essa via (interferon peguilado einfliximabe), nos anos de $2003 \mathrm{e}$ 2004, foram incluídos no Programa de M edicamentos Excepcionais, em 2002. No caso das determinações judiciais para o fornecimento de infliximabe haveria justificativa, uma vez que esse medicamento só foi padronizado pelo estado de Santa Catarina em 2004. Já no caso de interferon peguilado, a demanda judicial ocorreu prioritariamente para garantir o fornecimento do medicamento para pacientes que não se enquadravam nos critérios dos Protocolos Clínicos e Diretrizes Terapêuticas do M inistério da Saúde.

0 fato de que a maior parte dos processos judiciais determina o fornecimento de um único medicamento parece demonstrar queessa via tem sido empregada para assegurar o acesso não à assistência farmacêutica deuma forma geral, mas às novidades terapêuticas, cujo custo costuma ser tão el evado quetorna o Estado seu único comprador ${ }^{14}$. A frequente introdução de novos medicamentos contribui para o aumento dos custos de assistência à saúde. A contribuição desses novos medicamentos para a melhoria dos tratamentos requer uma investigação em si. Embora 
não seja o foco deste artigo, cabe destacar que a agência FDA, entre 1998 e 2003, aprovou 487 novosmedicamentos. Desses, 379 ( $78 \%$ ) foram classificados pela própria agência FDA como aparentemente tendo ações terapêuticas similares a outros produtos já comercializados, sendo que $333(68 \%)$ eram novas formulações ou combinações de produtos antigos e apenas 67 (14\%) dos 487 eram novos compostos, considerados prováveis inovações em relação aos fármacos mais antigos ${ }^{15}$.

Foram observadas situações em que as determinações judiciais obrigaram o Estado a fornecer medicamentos em indicações para as quais eles não estão aprovados no país. Essas situações são denominadas internacionalmente de uso off label. No Brasil, segundo a Anvisa, o uso off label não é proibido, mas o médico deve estar consciente de que a responsabilidade a respeito de eventuais efeitos colaterais decorrentes deum uso não aprovado do medicamento é do prescritor, estando o laboratório produtor isento de tal responsabilidade ${ }^{16}$. A questão do uso off label tem sido discutida geralmente em relação à responsabilidade do prescritor, no entanto, raramentetem sido apontada a necessidade deo usuário receber informações sobre os riscos de efeitos adversos ou de inefetividade do tratamento.

Outra observação diz respeito a casos de medicamentos que ainda não tinham seu registro aprovado pela Agência Nacional de Vigilância Sanitária. De forma regular, o acesso a medicamentos não aprovados no país pode ocorrer através da participação em ensaios clínicos de pacientes que supostamente possam se beneficiar deles, ou através de programas denominados "Programas de Acesso Expandido", que não se caracterizam como pesquisa clínica, e que várias indústrias farmacêuticas têm mantido desde a sua regulamentação. Em ambas as situações, 0 medicamento é fornecido pelas indústrias farmacêuticas, sem ônus para os pacientes ${ }^{17}$.

0 caso do gefitinibe éainda mais grave, pois além de não registrado no Brasil, a agência reguladora norte-americana (FDA) recomenda que pacientes que ainda não utilizaram esse medicamento não o utilizem, pois ele não demonstrou ser mais efetivo que as outras opções terapêuticas disponíveis ${ }^{18}$.

As situaçoes em que as determinações judiciais envolviam medicamentos padronizados se rão analisadas de acordo com os programas governamentais.
Medicamentos dos Programas

de Assistência Farmacêutica Básica

e Saúde M ental

Os medicamentos do Programa de Assistência Farmacêutica Básica devem ser disponibilizados pelos municípios. Portanto, somente no descumprimento do município quanto a isto se justificaria acionar a justiça para obtêlos. Entretanto, nos processos judiciais envolven do tais medicamentos, não havia informações a respeito de tentativas do paciente em buscar o medicamento em seu município e o produto estar em falta.

De forma similar, quando são analisados os processos solicitando medicamentosincluídos no Programa de Saúde M ental ( $n=17)$, observa-se que, na maioria dos casos, as cidades envolvidas contavam com Centro de Atenção Psicossocial (CAPS) ou possuíam serviços básicos de Saúde M ental (88\%). Dessa forma, os pacientes poderiam, em tese, ter sido inseridos no Programa de M edicamentos para a área da saúde mental para receberem o tratamento necessário. Também nesses casos, em nenhum processo há dados que indiquem que o paciente buscou atendimento e não encontrou o medicamento. Essas situações podem ser decorrentes da falta de informação quanto ao funcionamento dos programas ou do descrédito nas vias regulares.

\section{Medicamentos do Programa de Medicamentos Excepcionais}

Com relação aos medicamentos inseridos no Programa de M edicamentos Excepcionais, foram observados alguns casos em que os protocolos estabelecidos pelo M inistério da Saúde são restritivos e a via judicial parece ser a alternativa de acesso. Esses casos incluem situações em que:

(1) parece ser necessária ejustificável a ampliação do acesso aos medicamentos através de crité rios menos restritivos de inclusão no Programa. Exemplo disso é a disponibilização dos medicamentos formoterol e budesonida apenas para 0 tratamento da asma grave. Esta restrição faz com que pacientes portadores de doença pulmonar obstrutiva crônica (DPOC) ou com asma leve persistente e leve moderada, para os quais há indicação de uso de broncodilatadores e corticoides inalatórios, recorram à via judicial, salvo quando o município inclui algum medicamento em sua lista. Na situação exposta, é clara a necessidade deampliação dos critérios deinclusão dos pacientes junto ao Programa de M edicamentos Excepcionais, permitindo que portadores de 
DPOC e asma leve persistente e leve moderada possam ser atendidos.

Incluem-se aqui as solicitações de estatinas para pacientes com cardiopatia isquêmica. Atualmente, os critérios de inclusão utilizados pelos Protocolos Clínicos e Diretrizes Terapêuticas do Ministério da Saúde não contemplam pacientes com níveis de LDL-colesterol abaixo de $70 \mathrm{mg} / \mathrm{dl}$. No entanto, a literatura sugerea existência debenefícios com a utilização de estatinas para pacientes com cardiopatia isquêmica, independentemente dos níveis de LDL-colesterol que apresentem ${ }^{19-22}$.

(2) a restrição é claramente necessária, com base na literatura. N este estudo, a maioria dos pacientes que demandavam tratamento da hepatite viral $C$ através de processos judiciais apresentavam genótipo viral diferente de 1 , critério que os excluiriam do programa, segundo as diretrizes propostas pelos Protocolos Clínicos e Diretrizes Terapêuticas do M inistério da Saúde. O custo mensal por paciente para a Secretaria de Estado de Saúde, em 2004, utilizando o interferon peguilado associado a ribavirina, era de $\mathrm{R} \$$ $4.025,44$, em contraposição ao custo de $R \$ 123,12$ do tratamento com o interferon convencional associado à ribavirina. Portanto, o custo do tratamento com interferon peguilado era trinta ve zes maior do que com o interferon convencional. No entanto, os estudos clínicos ainda não demonstraram vantagens significativas na utilização do interferon peguilado em pacientes com genótipo viral diferente de ${ }^{23-28}$. N esse sentido, observa-se uma necessidade de conscientização dos prescritores e do Judiciário a respeito dos

\section{Colaboradores}

JR Pereira realizou a busca bibliográfica, a coleta e análise de dados, a discussão e redação do artigo; RI Santos participou da revisão da análise de dados e revisão do texto final; JM Nascimento Junior participou da revisão do texto final; EP Schenkel contribuiu com a revisão da análise de dados, revisão dos resultados, discussão e revisão do texto final. custos do tratamento com o interferon convencional e com o interferon peguilado, buscando a otimização da utilização dos recursos disponíveis. De acordo com a literatura, a utilização do interferon convencional nos pacientes com genótipo viral diferente de 1 não compromete 0 tratamento e proporciona melhor utilização dos recursos disponíveis.

Em suma, o conhecimento a respeito do funcionamento dos programas, dos critérios utilizados na seleção dos medicamentos que compõem esses elencos, deve ser disseminado, não apenas entre os prescritores, mas também entre os membros do Poder Judiciário. Deve-se ter em mente que os programas buscam possibilitar melhor alocação dos recursos financeiros e meIhor acompanhamento dos tratamentos estabelecidos. No caso específico dos medicamentos envolvidos nos processos judiciais, em vista do elevado custo, qualquer melhoria nos programas tem o potencial de disponibilizar um volume significativo de recursos para outras áreas.

Dessa forma, uma mel hor organização da assistência farmacêutica, proporcionando acesso mais simplificado aos tratamentos disponibilizados, revisões periódicas dos elencos sel ecionados e a conscientização dos prescritores e membros do Poder Judiciário acerca da lógica de funcionamento dos programas e de sua importância na utilização racional dos medicamentosena melhor alocação dos recursos disponíveis, mostra-se fundamental para reduzir a demanda judicial sem comprometer o direito constitucional à saúde.

Referências

1. 1. Bermudez JAZ, Bonfim JRA. M edicamentos e a reforma do setor saúde. São Paulo: Hucitec/Sobravime; 1999.

2. Schenkel EP, Rech N, Farias M R, Santos RI, Simões CM O. Assistência Farmacêutica. In: Brasil.

2. Ministério da Saúde. Saúde no Brasil. Ministério da Saúde: Brasília; 2004. 
3. Brasil. Congresso Nacional. Câmara dos Deputados. Comissão Parlamentar de Inquérito Destinada a Investigar os Reajustes de Preços e a Falsificação de M edicamentos, M ateriais Hospitalares e Insumos de Laboratórios. Relatório da CPI M edicamentos: relatório final da Comissão Parlamentar de Inquérito Destinada a Investigar os Reajustes de Preços e a Falsificação de M edicamentos, M ateriais H ospitalares e Insumos de Laboratórios. Brasília: Câmara dos Deputados; 2000. (Série ação parlamentar, 124).

4. Bortoletto ME, Bochner R. Impacto dos medicamentos nas intoxicações humanas no Brasil. Cad Saude Publica 1999; 15(4):859-869.

5. Bobbio N. Teoria geral da política: a filosofia política e as lições dos clássicos. Rio de Janeiro: Elsevier; 2000.

6. Santos MAC. A efetividade das normas constitucionais: as normas programáticas e a crise constitucional. Jus N avigandi 2004; 204. [acessado 2007 abr 29]. Disponível em: http://jus2.uol.com.br/doutrina/texto.asp?id $=4731$

7. Appio EF. 0 controle judicial das políticas públicas no Brasil [tese]. Florianópolis: Faculdade de Direito, Universidade Federal de Santa Catarina; 2004.

8. Marques SB, Dallari SG. Direito social à assistência farmacêutica. Rev Saude Publica 2007; 41(1):101-107.

9. Medscape Today. [acessado 2007 abr 25]. Disponível em: http://www.medscape.com/viewarticle/ 548002

10. M esseder AM, Castro CGSO, Luiza VL. Mandados judiciais como ferramenta para garantia do acesso a medicamentos no setor público: a experiência do estado do Rio de Janeiro, Brasil. Cad Saude Publica 2005; 21(2):525-534.

11. Constantino SF. Aumenta número de ações contra o SUS. Folha de S.Paulo 2005; ago $1^{\circ}$.

12. Vieira FS, Zucchi P. Distortions to National Drug Policy caused by lawsuits in Brazil. Rev Saude Publica 2007; 41(2):214-222.

13. Brasil. Instituto Brasileiro de Geografia e Estatística (IBGE). Pesquisa Nacional por Amostra de Domicílios (PNAD). Brasília: Instituto Brasileiro de Ge ografia e Estatística; 1998. [acessado 2005 abr 5] Disponível em: www.ibge.gov.br

14. Appio EF. 0 direito e a indústria: não cabe ao juiz determinar política pública de saúde. Consultor Jurídico 2005. [acessado 2005 dez 12]. Disponível em http://www.conjur.com.br/2005-nov-23/nao_cabe juiz determinar politica publica saude?pagina $=\overline{3}$

15. USA. Food and Drug A dministration. Center for Drug Evaluation and Research, Department of $\mathrm{H}$ ealth and Human Services. NDAs approved in calendar years 1990-2003 by therapeutic potentials and chemical types; 2004. [acessado 2006 fev 20]. Disponível em: www.fda.gov/cder/rdmt/pstable.htm

16. Brasil. Agência Nacional de Vigilância Sanitária. Como a Anvisa vê o uso off label de medicamentos; 2005. [acessado 2006 fev 15]. Disponível em www.anvisa.gov.br

17. Brasil. Agência Nacional de Vigilância Sanitária. Gerência de M edicamentos Novos, Pesquisa e Ensaios Clínicos. Esclarecimento sobre a posição da Anvisa quanto ao registro de medicamentos antineoplásicos novos; 2004. [acessado 2006 jan 3]. Disponível em http://www.anvisa.gov.br/divulga/ informes/2004/170204.htm
18. USA. Food and Drug Administration. FDA Statement on Iressa; 2004. [acessado 2005 ago 24]. Disponível em: http://www.fda.gov/bbs/topics/news/ 2004/new01145.html

19. Third Report of the National Cholesterol Education Program (NCEP) Expert Panel on Detection, Evaluation, and Treatment of High Blood Cholesterol in Adults (Adult Treatment Panel III) final report. Circulation 2002; 106:3143-3421.

20. Scandinavian Group. Randomised trial of cholesterol lowering in 4444 patients with coronary heart disease: the Scandinavian Simvastatin Survival Study (4S). Lancet 1994; 344(8934):1383-1389.

21. Collins R, Armitage J, Parish S, Sleigh P, Peto R. $\mathrm{H}$ eart protection study collaborative group. MRC/ BHF H eart Protection Study of cholesterol-lowering with simvastatin in 5963 people with diabetes: a randomised placebo-controlled trial. Lancet 2003; 361(9374):2005-2016.

22. Polanczyk CA, Ribeiro JP. Cardiopatia isquêmica. In: Duncan BB, Schmidt MI, Giugliani ERJ, organizadores. M edicina ambulatorial: condutas de Atenção Primária baseadas em evidências. 3a ed. Porto Alegre: Artmed; 2004. p. 704-711.

23. Lee SD, Yu ML, Cheng PN, Lai MY, Chao YC, H wang S), Chang WY, Chang TT, H sieh TY, Liu CJ, Chen DS. Comparison of a 6 -month course peginterferon alpha- $2 b$ plus ribavirin and interferon alpha- $2 b$ plus ribavirin in treating Chinese patients with chronic hepatitis C in Taiwan. J Viral Hepat 2005; 12(3):283-291.

24. Xie $Y, X u D Z$, Lu ZM, Luo KX, Jia JD, Wang YM, Zhao GZ, Zhang SL, Zhang DZ. Impact of virus genotype on interferon treatment of patients with chronic hepatitis C: a multicenter controlled study. Hepatobiliary Pancreat Dis Int 2004; 3(3):369-374.

25. Fried M W, Shiffman ML, Reddy KR, Smith C, Marinos $G$, Gonçales $F L J r$, Haussinger $D$, Diago $M$, Carosi G, Dhumeaux D, Craxi A, Lin A, Hoffman J, Yu J. Peginterferon alfa-2a plus ribavirin for chronic hepatitis C virus infection. N Engl J Med 2002; 347(13):975-982

26. M anns M P, M CHutchison JG, Gordon SC, Rustgi VK, Shiffman M, Reindollar R, Goodman ZD, Koury $K$, Ling $M$, Albrecht JK. Peginterferon alfa- $2 b$ plus ribavirin compared with interferon alfa- $2 b$ plus ribavirin for initial treatment of chronic hepatitis $\mathrm{C}$ : a randomised trial. Lancet 2001; 358(9286):958-965.

27. Lindsay $K L$, Trepo $C$, Heintges $T$, Shiffman $M L$, Gordon SC, Hoefs JC, Schiff ER, Goodman ZD, Laughlin M, Yao R, Albrecht JK. A randomized, double-blind trial comparing pegylated interferon alfa- $2 b$ to interferon alfa- $2 b$ as initial treatment for chronic hepatitis C. Hepatology 2001; 34(2):395-403.

28. Heathcote EJ, Shiffman ML, Cooksley GE, Dusheiko GM, Lee SS, Balart L, Reindollar R, Reddy RK, Wright TL, Lin A, Hoffman J. Peginterferon alfa-2a in patients with chronic hepatitis $\mathrm{C}$ and cirrhosis. $\mathrm{N}$ Engl J M ed 2002; 343:1673-1680.

Artigo apresentado em 04/11/2007

Aprovado em 23/11/2007

Versão final apresentada em 20/12/2007 